\title{
O
}

OLHARES

REVISTA DO DEPARTAMENTO DE EDUCAÇÄO - UNIFESP

\section{INTERNET E SEU IMPACTO PARA A EDUCAÇÃO SEGUNDO ANDREW FEENBERG}

\author{
INTERNET Y SU IMPACTO EN LA EDUCACIÓN SEGÚN ANDREW
}

FEENBERG

\section{INTERNET AND ITS IMPACT ON EDUCATION ACCORDING TO ANDREW FEENBERG}

\author{
Mauricio dos Reis Brasão \\ Universidade de Uberaba \\ mbrasao@gmail.com \\ Gustavo Araújo Batista \\ Universidade de Uberaba \\ mrgugaster@gmail.com
}

\begin{abstract}
Resumo: O presente trabalho objetiva sistematizar o arcabouço teórico feenberguiano da internet $e$ as possíveis implicações na educação. A pesquisa possui natureza teórica, com abordagem qualitativa e fundamentação fenomenológica, baseada nas contribuições de Bicudo (2011), e MerleauPonty (1999), cujo recorte teórico perpassa as obras de Feenberg (2002; 2010; 2017a; 2017b; 2019). Ao considerar o que faz sentido para o sujeito que percebe e se volta para a compreensão do fenômeno investigado, nota-se que: o ensino on-line diminui os custos com a educação, que tem constituído uma despesa considerável para estados e empresas; o medo de que a Internet substitua a relação entre professor e aluno não é algo novo, apenas reproduz uma crítica que também foi feita à escrita, mas, assim como esta trouxe novas possibilidades e progressos para a educação, a Internet também parece ampliar a aprendizagem. Portanto, se, por um lado, o avanço e a incorporação da Internet ao cotidiano já nos impõem sérias reflexões, por outro, seu impacto sobre a educação se revela considerável.
\end{abstract}

Palavras-chave: Educação e Internet. Andrew Feenberg. Tecnologias educacionais.

Resumen: Este trabajo tiene como objetivo sistematizar el marco teórico Feenbergiano de Internet y sus posibles implicaciones para la educación. La investigación tiene un carácter teórico, con un enfoque cualitativo y fundamento fenomenológico, basado en los aportes de Bicudo (2011) y MerleauPonty (1999), cuyo enfoque teórico permea los trabajos de Feenberg (2002; 2010; 2017a; 2017b; 2019). Al considerar lo que tiene sentido para el sujeto que percibe y vuelve a comprender el fenómeno investigado, se observa que: la enseñanza en línea reduce los costos de educación, lo que ha sido un gasto considerable para estados y empresas; El miedo a que Internet sustituya la relación entre profesor y alumno no es algo nuevo, solo reproduce una crítica que también se hizo a la escritura, pero, así como ha traído nuevas posibilidades y avances para la educación, Internet también parece expandirse. aprendizaje. Por tanto, si, por un lado, el avance y la incorporación de Internet a la vida cotidiana ya nos impone serias reflexiones, por otro lado, su impacto en la educación es considerable. 
Palabras clave: Educación e Internet. Andrew Feenberg. Tecnologías educativas.

Abstract: This paper aims to systematize the Feenberguian theoretical framework of the Internet and its possible implications for education. The research has a theoretical nature, with a qualitative approach and a phenomenological basis, based on the contributions of Bicudo (2011), whose theoretical framework traverses the works of Feenberg (2002; 2010; 2017a; 2017b; 2019). When considering what makes sense to the subject who perceives and turns to understanding the phenomenon investigated, the following situations are observed: online teaching reduces education costs, which has been a considerable expense for states and companies; and the fear that the Internet will replace the relationship between teacher and student is not a novelty, since it only reproduces a criticism that was also made to writing - just as the latter brought new possibilities and progress for education, the Internet also seems to expand learning. If, on the one hand, the advancement and incorporation of the Internet to daily life already impose serious reflections, on the other hand, its impact on education is considerable.

Keywords: Education and Internet. Andrew Feenberg. Educational technologies.

\section{Introdução}

A Internet é diferente de tudo na história da tecnologia que precedeu sua criação. Não é uma ferramenta e, tampouco, uma máquina, mas uma rede, um tipo de sistema técnico que se assemelha à telefonia em alguns aspectos, mas também possui semelhanças com redes de transmissão que distribuem entretenimento, mercadorias e sistemas de transporte, posto que abre novos "mundos" para os usuários. Além disso, os usuários da Internet adquirem novas capacidades e identidades por meio da participação na rede, mais obviamente com a absorção sem precedentes nas relações sociais mediadas, a exemplo do Facebook.

Nesses termos, a Internet abre muito mais janelas do que fecha de fato. Ela não apenas transporta indivíduos de um local para o outro; antes, constitui um mundo "virtual", em que a lógica da ação é participativa e a iniciativa individual, apoiada pela tecnologia, mais do que suprimida. Contudo, a Internet apoia uma visão harmoniosa de coexistência entre os homens e suas máquinas, uma rede que se situa no interior de uma grande transformação social, no contexto do desenvolvimento do modo de produção capitalista, da sociedade de informação, do fenômeno da globalização e da ressignificação das relações sociais a partir de inovadas formas de comunicação.

A pesquisa é de natureza teórica, com abordagem qualitativa, cuja fundamentação é a fenomenologia, ancorada nas contribuições de Bicudo (2011), e o recorte teórico perpassa as obras de Feenberg (2002; 2010; 2017a; 2017b; 2019). Obras que abordam a Internet, educação on-line e tecnologias educacionais.

Nesses termos, a fenomenologia vai às coisas mesmas para averiguar como o fenômeno se desvela; logo, o aspecto investigado é sempre situado/contextualizado. Assim, 
em um percurso que apresenta esse tipo de abordagem são esperadas, no próprio texto da descrição e em seu contexto, "características que se mostram relevantes ao pesquisador da perspectiva da questão norteadora" (BICUDO, 2011, p. 20).

A interrogação que expressa a perplexidade do pesquisador orienta os passos a serem dados para entender os elementos interpretados. Assim, apresenta-se o questionamento que moveu este estudo: qual a relação educação e internet no pensamento de Feenberg? Dessa maneira, almeja-se sistematizar o arcabouço teórico feenberguiano da internet e as possíveis implicações na educação, de acordo com quatro Unidades de Significado.

Em se tratando da primeira Unidade de Significado, são apresentados os significados da Internet; na segunda, utopia e distopia em relação à Internet; na terceira, críticas à Internet; e na última, a educação on-line.

Conforme o movimento da pesquisa, a concepção de educação abordada na pesquisa se aproxima da experiência descrita no pensamento heideggeriano, uma vez que o diálogo entre educação e tecnologia pode ser efetivado em uma nova perspectiva; também se transformar em um caminho possível, aprofundado e mediado por um viés crítico e reflexivo. Nessa compreensão, concebe-se a educação um processo de formação, estruturado ao modelo de sociedade em que ela ocorre.

\section{Os significados da Internet}

Ao final da década de 1960 nos Estados Unidos, a rede Internet surgiu com o propósito original de criar uma rede de comunicações para conectar os computadores da defesa americana. Nesse contexto, a Advanced Reasearch Project Agency (ARPA) desenvolveu a Arpanet, comunidade virtual que, em um primeiro momento, serviu para realizar comunicações via e-mail. Conforme Feenberg (2014):

A primeira versão do que se tornou a Internet foi disponibilizada on-line em 1969. O sistema recebeu o nome de Arpanet, elaborado pelo departamento estadunidense de defesa que se especializou nos projetos "blue sky", tão originais e especulativos que nenhuma agência governamental normal ousaria financiar. É interessante notar que, mesmo em um estágio tão precoce, muitos engenheiros envolvidos no projeto acreditaram que o trabalho teria repercussões enormes e benéficas. Eles profetizaram o surgimento de uma comunidade global estruturada por redes de computadores ${ }^{1}$ (FEENBERG, 2014, p. 6, tradução nossa).

\footnotetext{
1 "La première version de ce qui est devenu l'Internet a été mise en ligne en 1969. Ce système a été baptisé ARPANET, l'acronyme de Advanced Research Projects Agency du département états-unien de la Défense qui s'était spécialisé dans les projets 'blue sky', des projets si originaux et spéculatifs qu'aucune agence gouvernementale normale n'aurait osé les financer. Il est intéressant de noter que même à un stade si précoce, plusieurs des ingénieurs impliqués dans le projet croyaient que leur travail aurait d'immenses répercussions bénéfiques. Ils ont prophétisé l'apparition d'une communauté mondiale structurée par des réseaux informatiques" (FEENBERG, 2014, p. 6).
} 
Na década de 1970, a Arpanet passou a ser chamada de Darpanet ("D" significa "Defense", referindo-se à defesa americana). Com a ideia de criar uma rede internacional (internacional network), passou-se a utilizar a denominação Internet que, colocada em prática, se transforma "num sistema mundial público, de redes de computadores - numa rede de redes -, ao qual qualquer pessoa ou computador, previamente autorizado, pode conectar-se" (ALMEIDA, 2005, p. 4).

Janet Abbate (1999), ao tratar do desenvolvimento histórico da Internet, enfatiza os aspectos sociais e culturais e mostra como ela evoluiu de uma rede pequena que ligava os computadores da defesa americana para uma rede que passou a conectar milhões de computadores em todo o planeta. Ressalta-se que a Internet tem se revelado como uma rede flexível, em que foi projetada primeiramente com o propósito militar, mas se mostrava capaz de ganhar novas formas e servir a outros objetivos.

A Internet visa à comunicação de informações e às transferências de ideias. Ela se revela não como algo limitado à estrutura do computador, mas como um fenômeno dinâmico que reconfigura as relações sociais a partir de uma nova modalidade. Por mais que o projeto original da Internet visasse servir a propósitos militares, ela se tornou um meio de comunicação em massa. Desse modo, a história da rede mundial de computadores não obedece a um determinismo tecnológico, pois, em certo sentido, é caótica, e, em seu desenvolvimento, atuam forças não previstas que operam de modo a fazê-la assumir novas formas e receber novos sentidos (ABBATE, 1999).

Conforme Abbate (1999), o surgimento da Internet na década de 1960 se insere no contexto da Guerra Fria. Ela pode ser inserida na disputa tecnológica entre os Estados Unidos e a União Soviética que, em 1957 havia lançado ao espaço o satélite Sputinik, e isso desafiava os EUA a produzirem uma tecnologia mais avançada; assim, instaurou-se uma corrida frenética pelo desenvolvimento da tecnologia de informação. Não é estranho, pois, que a Internet tenha surgido com fins militares, isto é, para servir ao exército americano.

Conforme a perspectiva do olhar do pesquisador, foi possível observar que Feenberg (2014) pontua que a abertura gradual da Internet ao público ocorreu nas décadas de 1980 e 1990. A princípio, a Arpanet pretendia fazer testes e pesquisas juntamente a militares ligados às universidades - algumas delas foram conectadas por meio da rede mundial de computadores e, logo após, um engenheiro introduziu um programa de e-mail. Nos anos 1980, surgiu a ideia de uma educação on-line, e o desenvolvimento da Internet se mostrou mais visível na educação. 


\section{Utopia e distopia em relação à Internet}

O surgimento e o desenvolvimento da Internet produziram duas reações que podem ser consideradas exageradas. De um lado, os distópicos a viram como um grande perigo para a sociedade, com consequências políticas desastrosas e uso para fins maléficos; de outro, os utopistas viram, na rede mundial de computadores, a promessa de um futuro promissor, para promover uma nova era revolucionária e possibilitar desenvolvimento econômico. Desse modo, a discussão dos impactos da Internet frequentemente se situa em aspirações utópicas ou medos distópicos (FEENBERG, 2017b).

Feenberg (2017a) associa o distopismo às perspectivas contrárias à 'ameaça tecnocrática', como se vê em Martin Heidegger ${ }^{2}$, e o utopismo contemporâneo a expressões como o transumanismo ${ }^{3}$. A filosofia heideggeriana abarca um pensamento tecnológico que passa a determinar o ser-aí a partir do cálculo, e o transumanismo sonha com um futuro em que a tecnologia opera transformações da condição humana em um modo de ser melhorado. Corroboram Habowski e Conte (2019, p. 4), ao assinalarem que:

Tal distopia poderá ser superada por meio de projetos de iniciativa dos próprios utilizadores da internet ou por meio de intervenções democráticas de ambientalistas, por exemplo, quando acionada com base no desenvolvimento do potencial libertador da tecnologia (HABOWSKI; CONTE, 2019, p. 3).

Na conferência intitulada O Princípio do Fundamento, Heidegger (1998) cita a 'Era Atômica', momento histórico atual em que impera um pensamento calculador e tecnicista. Ele diz que, nesse período, o ser se apresenta no interior do universo da técnica compreendida conforme o pensamento calculador do ser-aí, da liberação da energia atômica e da automatização. O técnico é entendido como um plano projetado pelo ser-aí, mas que, ao mesmo tempo, força o ser-aí a decidir entre se tornar escravo do próprio plano ou permanecer senhor dele. Cumpre dizer que, na Era Atômica, a existência do ser-aí é devota ao planejamento, ao cálculo e à exploração de todos os elementos.

Conforme Heidegger (1998), o chamado que provoca o ser-aí a calcular e explorar tem o caráter de um "enquadramento" (Gestell), ou seja, aquilo em que (e de onde) o ser-aí é chamado no horizonte da técnica é um enquadramento. Este, por seu turno, agride o ser-aí

\footnotetext{
${ }^{2}$ Heidegger nasceu em 26 de setembro de 1889, em Messkirch, na Suíça alemã, e faleceu em 27 de maio de 1976, em Brisgóvia, Alemanha. Estudou Teologia e Filosofia na Universidade de Friburgo e foi filósofo, escritor, professor universitário, reitor e sucessor de Edmund Husserl na cátedra de Filosofia.

${ }^{3} \mathrm{O}$ transumanismo é uma controversa perspectiva de investimento na transformação da condição humana. Visando ao melhoramento biotecnológico da natureza humana, ele protagoniza o debate acerca do futuro (pós)humano. Na base da concepção transumanista está o investimento na biotecnociência como um modo de lluminismo humanista de raízes biológicas.
} 
em toda parte, por ser mais forte do que todas as energias atômicas e as máquinas; ele é mais poderoso do que a violência da própria informatização e automatização.

De acordo com Feenberg (2017b, p. 77):

Heidegger foi a influência mais poderosa do pensamento distópico no século XX. Sua Filosofia da Tecnologia é a combinação intrigante entre a nostalgia romântica para uma imagem idealizada da antiguidade e a profunda compreensão da modernidade. A originalidade reside no tratamento da técnica não apenas como um meio funcional, mas como um modo de "revelar" por meio do qual um "mundo" é formado. O "mundo" em Heidegger não se refere à soma das coisas existentes, mas a uma estrutura ordenada e significativa da experiência. Tais estruturas dependem de práticas básicas que caracterizam sociedades e épocas históricas por completo. Estes constituem uma "abertura" em que o "Ser" é "revelado" ao Dasein humano, ou seja, no qual a experiência ocorre ${ }^{4}$ (FEENBERG, 2017b, p. 77, tradução nossa).

Ou seja, Heidegger é o principal representante do distopismo em relação à tecnologia do século XX, com a maior influência em pensadores que a veem como ameaça. No entanto, ainda que a Filosofia da Tecnologia de Heidegger esteja envolvida no distopismo, em parte por causa do saudosismo em relação à antiguidade, ele apresenta uma compreensão profunda da situação em que se encontrava o ser-aí científico, isto é, o homem moderno. Para ele, a tecnologia não possibilita determinado desvelamento do mundo, a partir da abertura do ser-aí.

Quando Heidegger fala de Gestell, enquadramento, ele se refere a um tipo de abertura e descoberta do mundo, no qual tudo se apresenta como objeto da técnica. Assim, todo ente que vem ao encontro do ser-aí humano no interior do mundo é transformado em objeto tecnológico, com absorção do ser-aí pelo sistema tecnológico. Visto que os seres-aí se encontram absorvidos pela técnica, a tecnologia se torna uma força autogeradora que foge ao controle (FEENBERG, 2017b).

Em oposição ao distopismo, há o utopismo observado no transumanismo. Este, por sua vez, sonha com um hipotético futuro cenário pós-humano, em que a biotecnologia possibilitaria a construção de um novo ser na transformação de quem as pessoas são, em se tratando da formação de uma condição de ser inteiramente nova. Sendo assim, o transumanismo profetiza um futuro em que "o humano, por iniciativa própria e com vistas ao melhoramento da sua natureza, deixaria de ser humano" (VILAÇA; DIAS, 2014, p. 342).

\footnotetext{
4 "Heidegger was the most powerful influence on dystopian thinking in the 20th century. His philosophy of technology is a puzzling combination of romantic nostalgia for an idealized image of antiquity and deep insight into modernity. His originality lies in treating technique not merely as a functional means but as a mode of 'revealing' through which a 'world' is shaped. 'World' in Heidegger refers not to the sum of existent things but to an ordered and meaningful structure of experience. Such structures depend on basic practices characterizing societies and whole historical eras. These constitute an 'opening' in which 'Being' is 'revealed' to human 'Dasein', that is to say, in which experience takes place" (FEENBERG, 2017b, p. 77).
} 
Feenberg $(2010 ; 2017 a)$ discorre acerca de uma visão utópica intitulada 'sonho libertário', em que se preconiza uma sociedade livre, na qual cada sujeito poderia publicar seu livro na Internet sem precisar de editoras ou trabalhar sem precisar sair de casa. As pessoas teriam mais liberdade de escolher um gênero ante as múltiplas possibilidades de construção identitária e poderiam vivenciar novas formas de namoro e relacionamento virtual.

Utópicos veem a Internet como uma grande revolução social, cujos impactos poderiam ser comparáveis aos da Revolução Industrial. Embora a Internet certamente tenha tido um impacto considerável na sociedade, ela não inaugura uma nova era na história da humanidade (FEENBERG, 2017b).

Corroboram Habowski e Conte (2019, p. 4), ao assinalarem que:

A internet aproxima a interação e a coexistência entre sujeitos e suas máquinas, mas a condição própria desse conhecimento não é instrumento pacífico à satisfação de necessidades humanas, visto que tais necessidades naturais são desqualificadas ou desconsideradas.

Assim, conforme o movimento da pesquisa, não se pode comparar a Internet e a Revolução Industrial, pois esta provocou uma transformação radical das estruturas sociais, com o êxodo de grande parte da humanidade das fazendas rumo ao ambiente urbano. Parece não ser possível equiparar uma transformação tão radical da sociedade com os impactos da Internet.

\section{Críticas à Internet}

Quando se considera o surgimento da Internet e o respectivo uso na educação, percebe-se que as críticas não são de hoje. Para Feenberg (2002), a rede mundial de computadores não é a primeira tecnologia educacional a trazer transformações para o processo de ensino e aprendizagem, pois, quando surgiu, também causou mudanças e reflexões.

De acordo com o filósofo da tecnologia, no momento em que a escrita foi proposta como tecnologia educacional, entendia-se que ela não poderia substituir o discurso falado. Quando algo era ensinado na aula, o professor estava presente diante do aluno, o que não ocorreria quando uma pessoa lia um livro. Temia-se que a aprendizagem por meio da leitura fosse substituir a aula presencial e, assim, a presença do educador estaria ameaçada.

Platão foi um dos pensadores a criticar a escrita que tinha a potencialidade de destruir a aprendizagem dialógica e presencial entre docente e estudantes. Nas palavras de Feenberg (2002): "Platão sustenta que a tecnologia da escrita tem o poder de destruir a relação dialógica que deve unir professor e aluno. A tecnologia, sob a forma escrita, é a inimiga do toque 
humano, uma posição familiar dos críticos da vida moderna nos dias atuais"5 (FEENBERG, 2002, p. 116, tradução nossa).

Curiosamente, a mesma crítica tem sido feita contra a internet, como se ela fosse uma ameaça ao professorado. Feenberg (2002) assinala o fato de que, para refletir sobre a escrita, Platão se utilizava da própria escrita. Não surpreende, portanto, que os críticos da rede mundial de computadores a utilizem para apresentar seus pensamentos. Sempre que uma nova tecnologia educacional é introduzida, as críticas podem ressurgir.

Por trás desse tipo de crítica que apareceu primeiro em Platão 6 contra a escrita e que hoje é usado pelos críticos modernos contra a rede mundial de computadores, há a crença de que a qualidade de nossas interações é determinada pelo meio de comunicação utilizado. Ou seja, argumenta-se que o diálogo vivo e presencial é de maior qualidade do que a comunicação realizada por meio de um texto escrito ou via Internet.

No entanto, esse tipo de crítica é fundamentado em uma crença distorcida. Para Feenberg (2002) nota-se que a escrita, que embora seja diferente da interação dialógica presencial, levou a novas possibilidades que serviram ao registro e à transmissão de ideias. Isso também pode ocorrer com a Internet, que pode abrir espaço para outras oportunidades e despertar potencialidades. Do mesmo modo que a reflexão de Platão à escrita se mostrou injusta, parece que as críticas feitas à rede mundial de computadores e à educação on-line têm o mesmo teor.

Também há os que veem a educação automatizada com uma visão pessimista do desenvolvimento tecnológico. Geralmente se teme que as sociedades se transformem em tecnocracias distópicas e que a vida social seja controlada por um pensamento calculador (FEENBERG, 2002). Nesse entendimento, há cautela com uma "Era Atômica", para usar uma expressão de Martin Heidegger, filósofo alemão que criticava a sociedade tecnológica, ao argumentar que a vida seria determinada pela técnica, como se a tecnologia fosse dominar cada aspecto da existência, o que constitui uma ameaça terrível para a sociedade. Outros percebem a tecnologia como uma ameaça à democracia, uma abertura para a sociedade ser controlada por uma elite tecnocrata - tais críticas estão fundamentadas numa visão por demais pessimista da tecnologia.

Nesses termos:

As tecnologias não são meros meios para fins; elas também desenham mundos. Qual tipo do mundo é instituído pela Internet? $\mathrm{O}$ fato básico sobre a rede mundial de

\footnotetext{
5 "Plato holds that the technology of writing has the power to destroy the dialogic relationship that ought to join teacher and student. Technology in the form of writing is the enemy of the human touch, a position familiar from critics of modern life today" (FEENBERG, 2002, p. 116).

${ }^{6}$ Ver "Fedro: mito da origem da escrita". PLATÃO. Fedro: texto integral. São Paulo: M. Claret, 2001.
} 
computadores é a escassez da largura de banda. Essa limitação pode ser superada agora para o ponto em que o áudio e o vídeo podem ser distribuídos via Internet. Essa possibilidade inspira planos para a educação automatizada7 (FEENBERG, 2002, p. 124, tradução nossa).

Críticos da Internet geralmente indicam a necessidade de uma diferenciação entre o conhecimento como comunicação de conteúdo informativo e o saber como processo vivo de descoberta, que só seria possível nas interações comunicativas presenciais entre os humanos. Para o filósofo da tecnologia, seria possível criticar a educação on-line ${ }^{8}$ por não ser capaz de oferecer a construção de um conhecimento nesse segundo viés. No entanto, é necessário considerar que a Internet leva a novas formas de comunicação e interação humanas.

Pode-se salientar, a favor da Internet e para responder às críticas, que, além de não ser um obstáculo à comunicação, a rede mundial de computadores não é uma ameaça à sociedade democrática. Ao contrário, para o filósofo da tecnologia, a Internet possui também potencialidades democráticas, como a constituição em um ambiente dialógico, com espaço para a crítica cidadã. Assim, não parece ser consistente o argumento de que tal rede teria consequências não democráticas.

Também é importante discorrer que a Internet não é um produto acabado, tampouco está presa a um destino fixo e imutável. Ela ainda está em construção, evolução e desenvolvimento; logo, sua história não está acabada e não foi entregue como um produto pronto. Dessa maneira, as críticas à rede mundial precisam considerar esse aspecto flexível, ao entender as potencialidades e transformações abarcadas por ela.

Christian Fuchs ${ }^{9}$ (2008) "contribuiu com uma análise marxista inovadora da Internet, ao combinar as teorias do trabalho imaterial livre e a 'multidão' com a teoria da mercadoria do público"10 (FUCHS, 2008, p. 190, tradução nossa).

A partir de uma leitura marxista, Fuchs percebe o capitalismo avançado como uma sociedade da informação, na qual a produção de conhecimento é essencial para a reprodução do capital. O conhecimento é visto como produto que, embora seja essencialmente social e coletivo, se torna uma mercadoria no interior do modo de produção capitalista e é explorado

\footnotetext{
7 "Technologies are not mere means to ends; they also shape worlds. What kind of world is instituted by the Internet? The basic fact about computer networks is scarcity of bandwidth. This limitation can be overcome now to the point where audio and video can be distributed on the Internet. That possibility inspires plans for automated education" (FEENBERG, 2002, p. 124).

${ }^{8}$ Mais sobre educação on-line, ver: FEENBERG, (2017c).

${ }^{9}$ Christian Fuchs (1976-) é professor do Instituto de Pesquisa em Comunicação e Mídia da Universidade de Westminster, na Inglaterra. Dentre suas obras, destacam-se Internet and Society: theory in the information age, de 2008, e Social Media: a critical introduction, de 2014.

10 "Christian Fuchs has contributed an innovative Marxist analysis of the Internet combining the theories of free immaterial labor and the 'multitude' with audience commodity theory" (FUCHS, 2008, p. 190).
} 
por ela - os produtores de conhecimento, como é o caso dos pesquisadores acadêmicos, constituem uma classe explorada. Assim, esse tipo de exploração aumenta a mais-valia, quando se pensa na Internet como espaço de produção de conhecimento, uma mais-valia que passa a ser praticamente infinita (FEENBERG, 2015).

Fuchs (2008) desenvolve a ideia de digital labor ou trabalho digital, em que se inclui todo tipo de trabalho relacionado à produção de conteúdo nas tecnologias digitais. O próprio ato de navegar na Internet e de utilizar mídias sociais já seria, em certo sentido, uma forma de trabalho explorada pelo capitalismo e que produz mais-valia. Conforme Fuchs (2008): "Com a ascensão do capitalismo informacional, a exploração dos bens comuns se tornou um processo central de acumulação de capital"11 (FUCHS, 2008, p. 190, tradução nossa). Então, a rede mundial de computadores efetuaria uma mercantilização total da criatividade humana, e a produção de postagens nas redes sociais passa a ser um trabalho explorado pelo capitalismo (FEENBERG, 2015).

Feenberg (2015), no entanto, apresenta duas críticas à análise marxista de Fuchs: (i) ela ignora a diferença entre produção capitalista e produção na Internet, em que ambas não podem ser equiparadas, pois as informações fornecidas pelos usuários não funcionam com a produção de mais-valia - por conseguinte, o capitalismo lucra com diversas atividades que não são necessariamente trabalhistas, e a produção de informação na Internet é apenas uma delas; (ii) a rede mundial de computadores não é um fenômeno acabado, por ainda estar em fluxo, em evolução - não se sabe as novas formas que ela poderá ter ou os novos propósitos a serem assumidos. Desse modo, não se pode fazer uma crítica à Internet como algo acabado, sobretudo no tocante à televisão.

Em concordância com Feenberg (2015), Jodi Dean ${ }^{12}$ entende que a Internet apaga a lacuna entre significado e realidade - a distinção entre o que é real e verdadeiro e o que é simbólico e fantástico possibilita a resistência. Na Internet, todavia, a diferença entre o real e o irreal desaparece, e a diferenciação entre símbolo e coisa, fantasia e fato é essencial para a verdade e a resistência. Na Internet, o usuário é irreal para si mesmo, e os sujeitos possuem a ilusão de agirem politicamente, quando expressam opiniões ou assinam petições on-line, mas, na verdade, estão sendo vítimas de algo que poderia ser chamado de "fetichismo tecnológico" (FEENBERG, 2015).

\footnotetext{
11 "With the rise of informational capitalism, the exploitation of the commons has become a central process of capital accumulation" (FUCHS 2008, 190).

12 Jodi Dean (1962-) é americana e ensina teoria política. Dentre suas obras, destacam-se Aliens in America: conspiracy cultures from outerspace to cyberspace, de 1998, e Reformatting Politics: information technology and global civil society, organizada juntamente com Jon W. Anderson e Geert Lovink em 2006.
} 
Obviamente, a Internet seria prejudicial para a democracia, pois, para Dean (2005), a cultura tecnológica está relacionada à complexidade do capitalismo comunicativo e se insere nas relações de poder. Essa complexidade envolve a presença de desigualdades, exclusões e competições que ocorrem na sociedade de comunicação (SAMPAIO; BARROS, 2011).

Sobre o capitalismo comunicativo, Dean (2005) explica que:

[...] designa a forma de um capitalismo tardio em que os valores anunciados como centrais da democracia tomam forma material nas tecnologias de comunicação em rede. Ideais de acesso, inclusão, discussão e participação se realizam por meio de expansões, intensificações e interconexões da telecomunicação global. Mas, ao invés de levar a distribuições mais equitativas de riqueza e influência, bem como permitir o surgimento de uma variedade mais rica em modos de vida e práticas de liberdade, 0 dilúvio de telas e espetáculos compromete a oportunidade e a eficácia políticas para a maioria dos povos do mundo ${ }^{13}$ (DEAN, 2005, p. 55, tradução nossa).

Ou seja, o capitalismo comunicativo diz respeito a uma configuração do capitalismo avançado, como organização produtiva da sociedade fundamentada na tecnologia de informação. Nesse contexto são defendidas ideias democráticas, como as noções de inclusão, criação de espaços de discussão e divulgação de ideias. No entanto, na prática, esse tipo de capitalismo produz desigualdades sociais e prejudica politicamente a maior parte dos povos.

Feenberg (2015) não concorda completamente com a análise de Dean (2005), pois, apesar da influência de um pequeno número de sites populares na comunicação de determinadas informações, existe uma grande quantidade de variedades e espaços na Internet para exercer certa resistência.

Portanto, consciente da complexidade da Internet e da insuficiência tanto das análises distópicas, quanto das utópicas, Feenberg (2015) se embasa em um ponto de vista construtivista crítico que compreende a ambiguidade e as contradições da Internet que, nesse caso, não é unificada, mas é intrinsecamente complexa e conflituosa e se relaciona a forças sociais subjacentes. Portanto, a Internet é um campo de luta, e não uma 'coisa' ou substância definida e imutável.

Ao considerar tais ambiguidade e complexidade, Feenberg (2015) apresenta cinco camadas da Internet que revelam a multifuncionalidade de seus recursos: 1- estrutura não hierárquica; 2- anonimato; 3- difusão; 4- armazenamento de dados; e 5- comunicação.

\footnotetext{
13 "[...] designates that form of late capitalism in which values heralded as central to democracy take material form in networked communications technologies. Ideals of access, inclusion, discussion and participation come to be realized in and through expansions, intensifications and interconnections of global telecommunications. But instead of leading to more equitable distributions of wealth and influence, instead of enabling the emergence of a richer variety in modes of living and practices of freedom, the deluge of screens and spectacles undermines political opportunity and efficacy for most of the world's peoples" (DEAN, 2005, p. 55).
} 
Na estrutura não hierárquica, a Internet é uma rede disseminada, ao invés de um sistema centralizado como uma rede de transmissão. O anonimato protege qualquer forma de atividade estigmatizada ou antissocial, como o acesso à pornografia ou a expressão de opiniões impopulares, embora possa servir também a atividades criminosas.

Por sua vez, a difusão indica que a transmissão de informações na Internet tem potencial para atingir milhões. O armazenamento de dados tem funções variadas, incluindo fins comerciais, e, na comunicação, ela possibilita a interação recíproca de muitas pessoas entre si.

Diante do desenvolvimento histórico e das teorias sociais e políticas que discutem os impactos da rede mundial de computadores, cabe trabalhar o contexto em que essas influências são prementes, isto é, na educação. A aprendizagem na Internet apresenta um desafio, em que podem se apresentar tanto como aprendizes quanto como professores. A rede mundial de computadores permitiria um grau sem precedentes de conexão de conhecimento e experiência, com hiperaprendizagem tecnológica (DREYFUS, 2009).

Dreyfus (2009) questiona se a educação on-line pode substituir a aprendizagem pessoal que contempla a relação entre professor e aluno. Para isso, ele propõe a ideia de que a aprendizagem envolve cinco etapas para o aprendiz e discute se elas poderiam ser realizadas na EaD:

- Iniciante: o instrutor decompõe o ambiente de tarefas em recursos que podem ser reconhecidos pelo aprendiz. Para Dreyfus (2009), a educação presencial é melhor do que a EaD nessa etapa, pois apenas seguir as regras produzirá um desempenho ruim no mundo real. O aprendiz precisa não apenas de informações, mas também de uma compreensão do contexto em que elas fazem sentido.

- Iniciante avançado: à proporção que o iniciante lida com situações reais, ele começa a desenvolver uma compreensão dos aspectos relevantes; a partir disso, o aprendiz não se orienta mais por regras, e sim por máximas. Ao contrário de uma regra, uma máxima requer domínio e compreensão maiores das informações. A figura presencial do instrutor seria importante para cumprir o papel de um treinador, em que precisaria estar presente com o aprendiz na situação real em que o conhecimento deve ser aplicado.

- $\quad$ Competente: essa etapa exige uma quantidade considerável, em que o aprendiz deve planejar e escolher uma perspectiva específica, a fim de determinar os elementos da situação relevantes e ignorados. Desse modo, ele precisa ser capaz de se restringir aos aspectos mais relevantes para alcançar os objetivos. $\mathrm{Na}$ 
aprendizagem presencial, tal fase inclui um envolvimento emocional no planejamento e alcance dos objetivos que não poderiam ser vivenciados na educação on-line.

- Proficiente: um aprendiz nesse nível percebe o problema que precisa ser resolvido, mas precisa descobrir a resposta. A proficiência se alcança com experiência envolvida, de modo que tal fase não poderia ser atingida na EaD.

- Especialista: não apenas vê o que precisa ser resolvido, mas também o que deve ser feito imediatamente. $\mathrm{O}$ aprendiz precisaria assistir alguém que "é bom em fazer algo" para poder aprender por imitação - para se tornar um especialista, a EaD não seria suficiente.

- Mestre: em um primeiro momento, renuncia à "perspectiva apropriada" disponível em seus conhecimentos e escolhe deliberadamente uma nova perspectiva. Em um segundo momento, o novo comportamento se tornará parte do repertório intuitivo do mestre, que continuará crescendo com a experiência.

Dreyfus (2009) conclui, dessa forma, que o processo de aprendizagem requer envolvimento. $\mathrm{O}$ aprendizado só seria possível presencialmente, no envolvimento corporal com instrutores e outros aprendizes. Nesses termos, a EaD seria incapaz de produzir a experiência e o conhecimento necessários à aprendizagem.

Feenberg (2010) não compartilha dessa visão negativa sobre a EaD. Para ele, o primeiro argumento a favor do ensino on-line é que ela diminui os custos com a educação, que tem constituído uma despesa considerável para estados e empresas. O medo de que a Internet substitua a relação entre professor e aluno não é algo novo, pois Platão também temia que a escrita fosse prejudicial pelo mesmo motivo. Dreyfus (2009) apenas reproduz uma crítica que também foi feita à escrita, mas, assim como esta trouxe novas possibilidades e progressos para a educação, a Internet também parece ampliar a aprendizagem.

Este tópico foi capaz de mostrar o quanto a Internet é um fenômeno ambíguo e contraditório. Perspectivas distópicas e utópicas sobre ela são insuficientes para analisar o impacto social observado, sobretudo, na educação. A EaD tem sido muito debatida; no entanto, consegue-se esperar, da Internet, a abertura de novas possibilidades educacionais.

Ao ir-à-coisa-mesma, compreende-se que há três modelos de configurações possíveis da Internet no futuro, de acordo com Feenberg (2014): 1- modelo de informação, em que serviria para melhorar a disseminação de informações ao oferecer amplo acesso; 2- modelo de consumo, no qual a atividade econômica ligada aos mercados da Internet seria um elemento importante para a prosperidade das nações; e 3- modelo da comunidade, em que as pessoas poderiam avaliar o mundo ao redor e discutir as avaliações com os outros. 


\title{
4 Educação on-line
}

Discussões recentes na Internet enfatizam uma promessa de mudanças que são essenciais para as pessoas e, em nenhum domínio, estas são mais radicais do que na educação. O conteúdo substantivo do ensino pode agora ser melhor exercido pelos computadores do que por professores: ou se está indo na direção de uma transformação de juízos sobre a educação, posto que se entra na era pós-industrial da informação, ou, ao contrário, as pessoas têm testemunhado mudanças significativas na educação, porém mais modestas do que se julgam ser.

Como um participante no desenvolvimento inicial da educação on-line, Feenberg (2002) traz contribuições um pouco mais realísticas:

\begin{abstract}
O debate não se limita à educação, a qual é simplesmente uma dentre várias frentes de discussão para definir a sociedade do futuro. O significado da modernidade está em jogo nesse conflito. Uma possível consequência é a sociedade que reflete, em todas as suas instituições, a lógica da produção moderna, obcecada pela eficiência obtida por meio da mecanização e do gerenciamento. A Internet poderia servir a esse projeto tecnocrático em domínios intocáveis até agora, como o da educação. Mas alguém pode levar em consideração uma consequência bem diferente modelada não na fábrica, mas em outra instituição moderna: a cidade ${ }^{14}$ (FEENBERG, 2002, p. 114, tradução nossa).
\end{abstract}

Consoante o filósofo, a cidade é o lugar de interações cosmopolitas e comunicação aprimorada. Seu deus não é a eficiência, e sim a liberdade; não é dedicada à rígida reprodução do mesmo, do "mais fácil dos caminhos", mas ao teste flexível das possibilidades e ao desenvolvimento do novo; não se torna um controle hierárquico, e sim os contatos horizontais não planejados; e não diz respeito à simplificação e à padronização, mas à variedade e ao crescimento das capacidades requeridas para viver em um mundo mais complexo. Por isso, a questão implicada por Feenberg (2002, p. 115, tradução nossa), no cerne da tecnologia educacional, é: "Qual paradigma moldará o futuro da educação, o da fábrica ou o da cidade? ${ }^{15 "}$

A educação on-line pode servir a ambas as estratégias em diferentes configurações técnicas. Certamente, a educação automatizada é possível, apesar do preço a ser pago pela redefinição da própria educação. Nessa acepção, a generalização na Internet por meio de um conceito mais tradicional de educação, centrado na interação humana, facilitaria a

\footnotetext{
14 "The debate is not limited to education, which is simply one among several fronts in the struggle to define the society of the future. The meaning of modernity is at stake in this struggle. One possible outcome is a society reflecting in all its institutions the logic of modern production, obsessed by efficiency achieved through mechanization and management. The Internet could serve this technocratic project in hitherto protected domains such as education. But one can also envisage a very different outcome modeled not on the factory but on another modern institution, the city" (FEENBERG, 2002, p. 114).

15 "Which model, the factory or the city, will shape the future of education?" (FEENBERG, 2002, p. 115).
} 
participação de grupos que não recebem assistência e aumentaria o nível cultural da população.

Essa última perspectiva lembra um precedente significativo. É fato que o gradual desaparecimento do trabalho infantil e o consequente estabelecimento da educação universal transformaram as sociedades modernas e moldaram o tipo de pessoas que nelas vivem. $O$ quanto as pessoas são capazes de entender o complexo mundo tecnológico que as rodeia e de agir de maneira independente nele se deve ao tempo necessário para aprender o que as sociedades modernas permitem de fato. De acordo com Feenberg (2002, p. 115, tradução nossa): "No entanto, há uma forte ligação entre a educação e a divisão do trabalho, visto que, esta última tem determinando a primeira por muito tempo ${ }^{16 " ” .}$

Quando uma produção não especializada governa as expectativas educacionais, os níveis culturais permanecem relativamente baixos. Na visão de Marx citada por Feenberg (2002, p. 115, tradução nossa), "não há escapatória dessa situação enquanto o capitalismo sobreviver para impor sua divisão de trabalho ${ }^{17 " . ~ T o d a v i a, ~ o ~ c a p i t a l i s m o ~ e s t a ́ ~ v i v o ~ e ~ b e m, ~}$ mesmo depois de a demanda por habilidades técnicas ter crescido até abranger uma significativa fração da força laboral, cuja consequência tem sido um grande dinamismo educacional.

Portanto, conforme a perspectiva do olhar do pesquisador, foi possível observar segundo Feenberg (2002, p. 115, tradução nossa): a educação de adultos, por exemplo, "abraça agora mais de metade dos estudantes em programas universitários americanos, um reflexo da escassez de competências por parte da classe dos trabalhadores ${ }^{18}$.

Porém, quer-se saber quão longe irá essa tendência no capitalismo. Para o filósofo:

\begin{abstract}
Em primeiro lugar, a crescente demanda por trabalhadores escolarizados no avançado mundo capitalista é acompanhada da exportação de manufatura para os países pobres. Enquanto a mão de obra especializada e sindicalizada experiencia excessivas quedas de renda e no seguro trabalhista nos países desenvolvidos, padrões antigos de industrialização aparecem nos outros lugares. O efeito da 'Internet' deve levar a um crescimento global do trabalho não especializado, apesar de parecer o contrário em lugares como o Silicon Valley. Em segundo lugar, homens de negócio parecem estar cada vez mais alarmados com o alto custo da educação, a qual é, agora, o item de maior despesa em praticamente toda nação capitalista desenvolvida ${ }^{19}$ (FEENBERG, 2002, p. 115, tradução nossa).
\end{abstract}

\footnotetext{
16 "However, there is a strong link between education and the division of labor, with the latter determining the former over long periods" (FEENBERG, 2002, p. 115).

17 "[...] no escape from this situation so long as capitalism survived to impose its division of labor" (FEENBERG, 2002, p. 115).

18 "[...] now embraces more than half the students in American college programs, a reflection of the shortage of competencies in the labor pool" (FEENBERG, 2002, p. 115).

19 "In the first place, the growing demand for educated labor in the advanced capitalist world is accompanied by the export of manufacturing to poor countries. While skilled and unionized manufacturing workers suffer steep declines in income and job security in the advanced countries, old-fashioned patterns of industrialization appear everywhere else. The net effect may well be a global increase in deskilled work despite the contrary appearance
} 
A exemplo dos Estados Unidos, segundo o filósofo, a promessa da Internet inspirou uma ofensiva ideológica em favor da automatização e da educação não especializada. Tais problemas sugerem a contínua relevância da teoria crítica em relação à política educacional.

\section{Considerações finais}

Assim como o significado se manifestou à consciência do pesquisador, compreendese a relação das tecnologias educacionais com as sociedades democráticas e capitalistas, além de verificar como o processo tecnológico é perpassado por questões sociais e econômicas próprias. Assim, reflexões demandam ser feitas em torno das potencialidades democráticas da Internet e da maneira como a educação on-line se relaciona com as exigências produtivas do mundo capitalista. Significados socioeconômicos permitiram uma crítica a visões diatópicas e pessimistas em torno da rede mundial de computadores, ao revelar que ela não é um fenômeno acabado, e sim aberto.

Evidentemente, a educação on-line diminui os custos com a educação, que tem constituído uma despesa considerável para estados e empresas. As críticas modernas à Internet são similares àquelas realizadas na antiguidade contra a escrita e se equivocam ao informar que a qualidade é determinada pelos meios de comunicação, algo injusto e obsoleto. Ademais, pensar que a educação on-line irá substituir o professor é um mito, pois ela não é um material pedagógico, mas sim um meio de comunicação.

O medo de que a Internet substitua a relação entre professor e aluno não é algo novo, pois Platão também temia que a escrita seria prejudicial pelo mesmo motivo. Assim como esta última trouxe novas possibilidades e progressos para a educação, a Internet parece ampliar a aprendizagem de fato.

A tecnologia educacional desempenha um papel decisivo em defesa da reforma neoliberal, não por sua performance efetiva, mas, sobretudo, pela legitimação retórica do pretenso "progresso" promovido por ela. O futuro das tecnologias educacionais não está determinado, pois a Internet pode se associar às exigências do mercado e seguir a lógica produtiva do mundo industrial. Ela também pode se desenvolver em conformidade ao modelo da cidade, ao se constituir como um espaço livre de interação comunicativa entre as pessoas. Ambas as possibilidades estão abertas diante de uma tecnologia que não foi entregue como um produto acabado.

in places such as Silicon Valley. Second, business leaders appear to be increasingly alarmed by the high cost of education, which is now the largest budget item in practically every advanced capitalist nation" (FEENBERG, 2002, p. 115). 
De fato, a tecnologia não é apenas um meio ou uma vitória da humanidade sobre os processos mecânicos e repetitivos, como também um reflexo do desenvolvimento da natureza humana, à medida que se modifica com a transformação do mundo. Entende-se que a tecnologia educacional deve ser modelada pelo diálogo, em vez da lógica orientada para a produção da automatização.

Ao considerar o que faz sentido para o sujeito que percebe e se volta para a compreensão do fenômeno investigado, nota-se que críticos da Internet geralmente indicam a necessidade de uma diferenciação entre o conhecimento como comunicação de conteúdo informativo e o saber como processo vivo de descoberta, algo que seria possível apenas nas interações comunicativas presenciais entre os humanos. Pode-se também criticar a educação on-line por não ser capaz de proporcionar a construção de um conhecimento nesse segundo viés. No entanto, é necessário considerar que a Internet leva a novas formas de comunicação e interação humanas.

Em favor da Internet e para responder às críticas, salienta-se que, além de não ser um obstáculo à comunicação, a rede mundial de computadores não é uma ameaça à sociedade democrática. Ao contrário, para o filósofo da tecnologia, a Internet possui potencialidades democráticas, como a constituição de um ambiente dialógico, com espaço para a crítica cidadã. Assim, não parece ser consistente o argumento de que tal rede teria consequências não democráticas.

Também é importante discorrer que a Internet não é um produto acabado, tampouco está preso a um destino fixo e imutável. Ela ainda está em construção, evolução e desenvolvimento; logo, sua história não foi finalizada e/ou entregue como um objeto pronto. Críticas à rede mundial precisam considerar esse aspecto flexível, ao entenderem as potencialidades e transformações abarcadas por ela.

Com o escopo de desvelar o panorama de (des)caminhos que ainda precisam ser pensados e explorados no campo filosófico e educativo das tecnologias, são elencadas algumas propostas que podem inspirar futuras investigações: 1 - discussões sobre questões éticas, deontológicas, culturais e político-sociais; 2 - abordagens sobre educação e tecnologia remota; 3 - ponderações políticas na perspectiva da tecnologia e educação; 4 transformações da tecnologia por meio da educação; 5 - considerações da tecnologia no mundo contemporâneo; e 6 - observações acerca das tecnologias no distanciamento social.

Assim como o fenômeno se mostra para o pesquisador, em que a percepção é a própria matéria que adquire sentido e forma, desvela-se que, uma abordagem dialógica da educação on-line deveria prevalecer em escala suficientemente grande, o que pode ser um 
fator decisivo para mudanças sociais fundamentais. Essa perspectiva e suas implicações utópicas podem ser exploradas na íntegra da pesquisa de doutorado de Brasão (2020).

\section{Referências}

ABBATE, Janet. Inventing the Internet. Cambridge and London: The MIT Press, 1999.

ALMEIDA, José Maria Fernandes de. Breve história da Internet. Portugal. Universidade do Minho, Departamento de Sistemas de Informação, 2005.

BICUDO, Maria Aparecida Viggiani. (Org.). Pesquisa qualitativa segundo a visão fenomenológica. São Paulo: Cortez, 2011.

BRASÃO, Mauricio dos Reis. A fundamentação teórica da tecnologia segundo Andrew Feenberg: implicações na educação à luz da fenomenologia. 487f. 2020. Tese (Doutorado em Educação) - Universidade de Uberaba, Uberaba, 2020.

DEAN, Jodi. Communicative Capitalism: circulation and the foreclosure of politics. Cultural Politics, v. 1, p. 51-74, 2005.

DREYFUS, Hubert L. On the Internet. 2. ed. London and New York: Routledge, 2009.

FEENBERG, Andrew. A polêmica Educação online e o futuro da universidade.

Tradução de Maureen Mourning. Tradução do artigo The Online Education Controversy and the Future of the University. [S. I.: s. n.], 2017c. Disponivel em:

https://www.sfu.ca/ andrewf/a\%20polemica.pdf. Acesso em: 2 jun. 2021.

FEENBERG, Andrew. Between Reason and Experience: Essays in Technology and Modernity. Cambridge: The MIT Press, 2010.

FEENBERG, Andrew. Entre a razão e a experiência: ensaios sobre tecnologia e modernidade. Tradução Eduardo Beira com Cristiano Cruz e Ricardo Neder. [S. I.]: MIT Portugal, 2017a.

FEENBERG, Andrew. Technosystem: The Social Life of Reason. Cambridge: Harvard University Press, 2017b.

FEENBERG, Andrew. Tecnologia, modernidade e democracia. Organização e tradução: Eduardo Beira. Lisboa: MIT Portugal, 2015. Disponível em:

https://www.sfu.ca/ andrewf/TECNOLOGIA_MODERNIDADE_DEMOCRACIA.pdf. Acesso em: 8 jun. 2021.

FEENBERG, Andrew. Transforming Technology: A Critical Theory revisited. New York: Oxford University Press, 2002.

FEENBERG, Andrew. Vers une théorie critique de l'Internet. tic\&société, [s. I.], v. 8, n. 1-2, p. 31-56, 2014. Disponível em: https://www.sfu.ca/ andrewf/vers\%20une\%20theorie.pdf. Acesso em: 7 jun. 2021.

FUCHS, Christian. Internet and Society: social theory in the information age. New York: Routledge, 2008. 
HABOWSKI, Adilson Cristiano; CONTE, Elaine; FEENBERG, Andrew. Entre a razão e a experiência: ensaios sobre tecnologia e modernidade. Conjectura: Filosofia e Educação, Caxias do Sul, v. 24, p. 1-7, 2019. Disponível em:

http://www.ucs.br/etc/revistas/index.php/conjectura/article/view/7388. Acesso em: 28 maio 2021.

HEIDEGGER, Martin. O princípio do fundamento. Lisboa: Instituto Piaget, 1998.

SAMPAIO, Rafael Cardoso; BARROS, Chalini Torquato Gonçalves de. Internet como esfera pública? Análise de usos e repercussões reais das discussões virtuais. Estudos em

Comunicação, Salvador, n. 9, p. 161-183, 2011. Disponível em:

https://portalseer.ufba.br/index.php/ppgau/article/view/5114/3703. Acesso em: 9 jun. 2021.

MERLEAU-PONTY, Maurice. Fenomenologia da Percepção. Tradução de Carlos Alberto Ribeiro de Moura. 2. ed. São Paulo: Martins Fontes, 1999.

OLIVEIRA, Joelson Roberto. Nietzsche e o Transhumanismo: em torno da questão da autossuperação do homem. Kriterion, Belo Horizonte, n. 135, Dez./2016, p. 719-739.

VILAÇA, Murilo Mariano; DIAS, Maria Clara Marques. Transumanismo e o futuro (pós-) humano. Physis: Revista de Saúde Coletiva, Rio de Janeiro, v. 24, n. 2, p. 341-362, 2014. Disponível em: http://www.scielo.br/scielo.php?pid=S0103-

73312014000200341\&script=sci_abstract\&tlng=pt. Acesso em: 9 fev. 2021.

\section{Agradecimentos}

Ao meu orientador, Prof. Dr. Gustavo Araújo Batista (UNIUBE), pela confiança, dedicação, estímulo e respeitoso diálogo na orientação rigorosa e motivadora ao longo do árduo processo de doutoramento.

Aos professores doutores José Carlos Souza Araújo (UFU/UNIUBE) e Martha Maria Prata-Linhares (UFTM), pelas contribuições valiosas que me ofereceram no momento do exame de qualificação. A todos os professores do Programa de Pós-graduação em Educação da Uniube, por compartilharem comigo seus conhecimentos e experiências.

À Fundação de Amparo à Pesquisa do Estado de Minas Gerais (FAPEMIG), pelo apoio na realização da pesquisa. 